\title{
Global, national, and local approaches to mental health: examples from India
}

\section{Citation}

Weiss, Mitchell G., Mohan Isaac, Shubhangi R. Parkar, Arabinda N. Chowdhury, and R. Raguram. 2001. "Global, National, and Local Approaches to Mental Health: Examples from India." Tropical Medicine and International Health 6 (1) (January): 4-23. doi:10.1046/j.1365-3156.2001.00670.x.

\section{Published Version}

doi:10.1046/j.1365-3156.2001.00670.x

\section{Permanent link}

http://nrs.harvard.edu/urn-3:HUL.InstRepos:34864853

\section{Terms of Use}

This article was downloaded from Harvard University's DASH repository, and is made available under the terms and conditions applicable to Other Posted Material, as set forth at http:// nrs.harvard.edu/urn-3:HUL.InstRepos:dash.current.terms-of-use\#LAA

\section{Share Your Story}

The Harvard community has made this article openly available.

Please share how this access benefits you. Submit a story.

\section{Accessibility}




\title{
Global, National, and Local Approaches to Mental Health: Examples from India
}

\author{
Mitchell G. Weiss, MD, PhD, ${ }^{1}$ Mohan Isaac, MD, ${ }^{2}$ Shubhangi R. Parkar, MD, ${ }^{3}$ \\ Arabinda N. Chowdhury, MD, PhD, ${ }^{4}$ and R. Raguram, MD ${ }^{5}$
}

Accepted for publication as first in series on

Global, National, and Local Health Policies and Programmes

In

Tropical Medicine and International Health

5 January 2001

Not for quotation, citation, or distribution without permission

${ }^{1}$ Professor and Head, Department of Public Health and Epidemiology, Swiss Tropical Institute, Socinstrasse 57, CH-4002 Basel, Switzerland. E-mail: Mitchell-G.Weiss@unibas.ch

${ }^{2}$ Professor and Head, Department of Psychiatry, National Institute of Mental Health and Neuro Sciences, Bangalore, India

${ }^{3}$ Professor and Head, Department of Psychiatry, KEM Hospital and Seth GS Medical College, Mumbai, India

${ }^{4}$ Professor and Head, Department of Psychiatry, Institute of Postgraduate Medical Education and Research, Calcutta, India

${ }^{5}$ Additional Professor of Psychiatry, National Institute of Mental Health and Neuro Sciences, Bangalore, India 


\begin{abstract}
Neuropsychiatric disorders and suicide amount to $12.7 \%$ of the global burden of disease and related conditions (GBD) according to WHO estimates for 1999, and recognition of the enormous component of mental illness in the GBD has attracted unprecedented attention in the field of international health. Focussing on low- and middle-income countries with high adult mortality, this article discusses essential functions of international agencies concerned with mental health. A review of the history and development of national mental health policy in India follows, and local case studies consider the approach to planning in a rural mental health programme in West Bengal and the experience in an established urban mental health programme in a low-income community of Mumbai. Local programmes must be attentive to the needs of the communities they serve, and they require the support of global and national policy for resources and the conceptual tools to formulate strategies to meet those needs. National programmes retain major responsibilities for the health of their country's population: they are the portals through which global and local interests, ideas, and policies formally interact. International priorities should be responsive to a wide range of national interests, which in turn should be sensitive to diverse local experiences. Mental health actions thereby benefit from the synergy of informed and effective policy at each level.
\end{abstract}




\section{Global, National, and Local Approaches to Mental Health:}

\section{Examples from India}

International health is increasingly concerned with achieving its objectives through an effective mix of global, national, and local policymaking and action. In this review we focus on mental health, which has recently come to the fore on the agenda of international health in low- and middle-income countries, critically examining the distinctive roles of health policy and planning at each of these three levels. We proceed by examining essential functions of international agencies for mental health policy, especially WHO. An account of the history and development of mental health policy in India provides a case study at the national level, and as local case studies we consider the approach to planning a new mental health programme for an underserved rural area of the Sundarban Delta, West Bengal, and experience in an ongoing programme of a low-income urban community in Mumbai (formerly Bombay).

Globalization, which energizes many of these reflections, has become a controversial topic; its power and impact on the world order bring opportunities for some people and pose threats to others (McMichael \& Beaglehole, 2000). More complex and less coherent than it is popularly portrayed, the character of globalization and its implications for entrepreneurs, consumers, and development strategists may differ substantially. As a complementary pair, globalization and localization may also prove to be powerful forces for promoting economic development for the disadvantaged in low- and middle-income countries, and this premise has been examined closely as the theme of the World Bank's annual World Development Report for 1999/2000 (World Bank 2000). Insofar as globalization and localization are conceived as competing, rather than complementary, controversy concerning adverse 
implications of globalization is reminiscent of earlier international health policy debates on other contested topics, such as central planning vis-à-vis decentralization, comprehensive visà-vis selective primary health care, and vertical vis-à-vis horizontal health planning (Mosley 1988). Having debated these issues intensely over the past several decades, the field of international health is now wary of dogmatic ideologies and sweeping global policy. The editor of the Bulletin of W.H.O., Richard Feachem, elaborated this point in a recent editorial, arguing that "The global and idealistic prescriptions of the 1970s must be jettisoned in favour of policy formulation and evaluation grounded in the disparate realities of where countries are today" (Feachem 2000).

National health policy is typically the portal through which global and local policies formally interact. Although the authority of nations has been undermined both by globalization and fragmentation from localization, nations remain responsible for the health of their people (Jamison et al. 1998). Under the influence of these complementary forces-globalization, which "brings distant parts of the world functionally closer together" and localization, which highlights the multiplicity of locally distinctive "policy environments" (World Bank 2000)—important questions arise about the interrelationship of different levels of health policymaking. How should they interact? What are the particular strengths and limitations of policy and action at each of these levels? How can these interactions be managed to ensure that higher-level policy is rooted in local experience, and local action benefits from support and relevant experience elsewhere? Such questions are applicable to many aspects of health and development.

Because mental health has now assumed a more prominent place on the agenda of international health and development, questions of what to do about it have become more significant. A shift in the values and priorities of international health resulted from the 
development and influence of the disability-adjusted life year (DALY) as an indicator of disease burden (Murray \& Lopez 1996a; World Bank 1993). The DALY acknowledged the impact of disability and corrected the prior overemphasis on mortality as a guide to health policy. It has also been subject to serious criticism, however, and some critics within WHO have argued that its contribution was mainly academic, and that at the current level of development it is inadequate for prioritizing health problems or guiding resource allocation (Sayers \& Fliedner 1997). Other critics are concerned that the concept promotes a curative, rather than health promotive, agenda and thereby subverts the aims of primary health care (Baru \& Jesani 2000). Various technical limitations are also a matter of serious concern, such as opaque calculations, inadequate data, and questionable extrapolations from available data. According to a critical appraisal, these limitations compromise the broad-based utility of the concept, and they also result in underestimates of the impact of some health problems, particularly the burden of sexual and reproductive disorders (AbouZahr \& Vaughan 2000). Although such controversy persists, the DALY has withstood these challenges and has become an influential indicator, used by WHO to track the burden of diseases and related conditions. It is now invoked frequently in deliberations on global health priorities.

\section{Priority of Mental Health}

Based on estimated DALYs, WHO reports that in 1999 neuropsychiatric conditions accounted for $11.0 \%$ of the global burden of disease (GBD), or $10.8 \%$ if we focus on conditions most pertinent to mental health by excluding multiple sclerosis and Parkinson disease. Taking suicide into account adds another $1.7 \%$ to the mental health-related component of the GBD (WHO 2000a) (Figure 1). The WHO account of the GBD for 1998 was disaggregated differently. It compared the disease burden in regions according to income 
status for "low- and middle-income" and "high-income" countries (globally and for the six regions), and found that in high-income countries the estimates of neuropsychiatric illness (23.5\%) and intentional self-injury (2.2\%) were greater (WHO 1999a). Estimates for 1999 in WHO's World Health 2000 report, however, make comparisons across mortality (rather than economic) strata, with reference to child and adult mortality groups. Based on these data, with globally grouped comparisons for four adult mortality strata, table $\mathbf{1}$ shows the wide variation in the relative role of mental health problems. Mental health-related DALYs as a percentage of the total burden range from $3.9 \%$ in very high mortality countries of Africa to $24.6 \%$ in very low adult mortality countries of Europe, America, and the Western Pacific regions.

This does not mean, of course, that mental health is substantially less of a problem in higher mortality countries, but rather, that because of the various other problems in pre-health transition countries, the relative role of mental health problems is less. Table 2 shows that the absolute burden of mental health-related DALYs is similar across mortality strata. Furthermore, it is likely that because of competing priorities and weaker infrastructure, data from high-mortality countries underestimate the absolute burden of mental illness, which one might expect to be higher owing to greater stress (Walker 1996). Common mental disorders are less likely to be identified where health services are few, demands pressing, and mental health training minimal or nil.

Projections that consider the anticipated effects of development on the epidemiological health transition suggest that the proportion of mental health problems in the GBD is likely to increase dramatically (an assertion supported by the current per capita data in table 2), reaching $15 \%$ by the year 2020 (Jenkins 1997; Murray and Lopez 1996b). Unipolar major depression is expected by then to be the second leading cause of DALYs lost. Even for 1998 estimates, among persons aged 15 - 44, 5 of the 10 leading causes of disability in low- 
and middle-income countries were already identifiable as mental health-related or behavioural problems.

Suicide rates, which are presented in the category of intentional self-injury in WHO's world health reports, also appear to be higher in lower-mortality countries, where they are also a higher percentage of all deaths (Table 3). Rates of suicide, however, are likely to be underestimated, and even more so in higher-mortality than lower-mortality countries because of weak infrastructure and reporting mechanisms. The percentage of deaths by suicide is lower in higher-mortality countries not only because of the likelihood of underestimated rates but also because there are so many deaths from other causes.

Recognizing the priority of mental health, international health agencies are now grappling with the challenge of what to do about it, as they strive to formulate effective policy (Brundtland 2000; Üstün 2000). The World Bank has appointed special advisors for mental health to promote intersectoral collaboration sensitive to the interests of mental health in the Bank's projects. National health ministries, cannot of course base priorities solely on a global agenda, since they must also consider experience at provincial, district, and local levels, where views of mental health issues are likely to have a different character. At the local level, it is not so much the epidemiological statistics, based on precisely defined diagnostic criteria, that spark the interest and capture the attention of the people and their leaders. In his remarks for a mental health policy roundtable discussion organized by WHO (WHO 2000b), N. N. Wig, a leading figure in Indian psychiatry and former WHO mental health advisor, explained that communities define mental heath needs differently from mental health professionals. "When public leaders talk of mental health, their concern is with the rising stress in life, alcohol and drug abuse, suicides, street violence, broken families, and the like" (Wig 2000, p.503). Both 
professional data and a local formulation of mental health priorities have a role to play in mental health planning.

In the next sections we discuss the essential functions of the international mental health system and thereafter provide national and local case studies. Low-income and high-mortality countries of the world are vastly different with respect to their cultures, social structures, and health systems. We have chosen India as an example for several reasons. Its size makes it significant and compelling; despite its status as a low-income, high-mortality country, the infrastructure of psychiatry and mental health is better developed than in many other countries in this category. Shifting priorities and changes in the structure of the mental health system over the course of its development illustrate the effects of a colonial history, changes in international priorities, and both globalizing and localizing forces. Just as no single country can provide a fully adequate case study for low- and middle-income nations of the world, in a country so large and diverse as India, no single local programme can be clearly representative. Nevertheless, it is instructive to consider from discussion of global approaches and the national and local case studies how each supports the three pillars of public mental health policy: contributing to effective treatment or appropriate referral of patients with mental health problems, preventing preventable mental illness, and promoting mental health (Weiss et al. 2000; Tansella 2000).

\section{Global mental health system}

Although there may be different ways of construing the responsibilities of international agencies concerned with mental health, we suggest the following formulation of essential functions: (1) examining the burden of mental illness in cross-national studies; (2) devising frameworks for diagnosis and assessment in clinical practice and research; (3) 
comparing the structure and performance of mental health systems; and (4) formulating priorities and policy, and supporting programmes to promote mental health, and to prevent and treat mental illness and related conditions.

The analysis of essential functions by Jamison and colleagues (1998) distinguishes core functions and supportive functions. Adapting this framework to mental health, we expect core functions to be concerned with interests and activities of broad international interest. Supportive functions involve mental health actions that assist national or local programmes pursuing objectives in settings with insufficient resources. Insofar as the essential functions listed above represent fundamental issues in the field that have broad significance beyond the interests of a single country, these constitute core functions, especially the first three. Assistance to specific programmes, as is most likely to be included under point 4, constitutes a supportive function. We briefly discuss the nature of essential functions and global mental health actions in each of the four domains.

\section{Examining the burden of mental illness}

Developing the tools and designing research to clarify the burden of mental illness and related conditions, such as suicide (which is frequently associated with mental illness, but not a mental disorder per se), has been a high priority for mental health at WHO over the past four decades. Undertaken in the 1960s, WHO's development of cross-national epidemiological studies, beginning with the International Pilot Study of Schizophrenia (IPSS), helped to define an agenda for psychiatric epidemiology. Other large-scale studies followed, and recently, the most comprehensive epidemiological study of mental disorders ever, the World Mental Health 2000 Initiative, has been planned through an International Consortium in Psychiatric Epidemiology (ICPE) involving an extensive network of collaborators (WHO- 
ICPE 2000; Üstün 1999). Collecting surveillance data on suicides and mental disorders that are provided from member countries provides additional valuable information for promoting mental health (WHO 1999b).

Other aspects of the burden of mental illness were highlighted in the World Mental Health Report (Desjarlais 1995), prepared by a group at Harvard Medical School. Reviewing the specific character and contexts of mental illness in low- and middle-income countries, it highlighted the importance of social and cultural aspects of health, illness, and suffering. It recognized a spectrum in the relationship between emotional distress and disorder and considered the impact of widespread social disruptions, the needs of special populations (such as women and minorities), and a broader view of the burden of mental illness beyond the epidemiological framework of psychiatric disorders.

Applying this broader contextual approach to mental health, WHO's Nations for Mental Health Programme has defined a so-called hidden burden and an undefined burden of mental illness. The hidden burden refers to the social consequences, rather than psychopathology, which results in unemployment, stigmatization, humiliation, and human rights violations. The undefined burden refers to the adverse impact arising indirectly from social and economic effects of mental illness on the families, colleagues, and communities of people with a mental illness. An economic analysis of mental health, of which there are few in low-income countries (Shah \& Jenkins 2000), might also consider the impact of mental health problems on social capital and community development (Lomas 1998).

\section{Devising frameworks for diagnosis and assessment}

The international mental health system defines diagnostic and other appropriate frameworks to guide clinical practice and research, and to facilitate cross-national 
comparisons. Both WHO and the American Psychiatric Association (APA) have worked independently and with some collaboration to create manuals for the diagnosis and classification of mental disorders. Since the 1960s, with the development of the APA's criterion-based diagnostic system embodied in the third revision of the Diagnostic and Statistical Manual of Mental Disorders (DSM-III), nosology has become a major focus of attention in psychiatry.

In low- and middle-income countries, culturally distinctive features of mental illness that are neglected in the international diagnostic manuals may make them difficult to use. Efforts to discuss the cultural features of specific mental disorders and to define a cultural formulation for assessment and practice in diverse international settings and in increasingly multicultural cities were represented in DSM-IV (Weiss 2000), and these issues are likely to be featured more prominently in the next editions of the APA and WHO manuals (DSM-V and ICD-11). The cultural formulation facilitates bidirectional interaction between local clinical experience and the global diagnostic system. Without such efforts to acknowledge cultural diversity and regional differences, the need for more culture-specific regional and national nosologies as guidelines to clinical practice and research would surely become more compelling. For example, a Chinese Classification of Mental Disorders has already been developed (Lee 1996), and in other countries, such as India, the call for a more culturally valid national classification system is a recurring, controversial theme. A fundamental question for diagnosis and classification persists: to what extent and how should local priorities and the priorities of an international standard mutually accommodate one another?

Instruments and frameworks for research, based on the international nosologies, are available for both clinical and community epidemiological studies. Some of these, such as the Structured Clinical Interview for DSM-IV (SCID), have been developed in the United States 
and keyed to the DSM system, and others were developed at WHO and keyed initially to the ICD system, although recent versions are keyed to both the ICD and the DSM (eg, the Composite International Diagnostic Interview [CIDI], and the Schedules for Clinical Assessment in Neuropsychiatry [SCAN]). These instruments have been developed for research in psychiatric epidemiology, on which DALY estimates for mental health problems rely.

The need for additional frameworks to clarify cultural features of illness in a cultural epidemiology of illness experience, meaning, and behaviour has also been recognized among the interests of public health. (Weiss et al. 2000). Such a cultural epidemiology of mental illness helps to shape policy and practice in diverse settings or among diverse populations, just as the epidemiology of mental disorders informs the DALY accounts, which indicate needs and inform priorities. The tasks of psychiatric and cultural epidemiology are complementary.

\section{Comparing the structure and performance of mental health systems}

Mental health policy is concerned with a diverse agenda that aims to improve the mental health status of populations by providing clinical services and treatment, preventing mental illness or minimizing progression of emotional distress to mental disorder, and promoting mental health. A framework for analysis and evaluation of health systems, recently developed by WHO and presented in the current World Health Report 2000, refers to various health actions with reference to general health priorities that are also applicable or adaptable to mental health. New indicators have been introduced and advocated in this World Health Report to specify and track the health status of populations and the performance of health systems each year in the World Health reports. 
Appropriate indicators and frameworks for evaluating the structure and performance of mental health systems are badly needed to inform policy in low- and middle-income countries. It is hoped that the World Health Report for 2001, for which mental health is the theme, will address this need. The framework developed in the World Health Report 2000 provides a starting point (WHO 2000a; Feachem 2000; Murray \& Frenk 2000), which needs to be modified and adapted for mental health systems. One may begin by asking how the fundamental goals of that framework may be adapted and applied to consider the mental health status of populations, responsiveness of the system to users, and equity in the distribution of its costs and accessibility. Assessments for each of these mental health system goals are complex, especially responsiveness, which must consider both professionally defined and locally perceived needs, as well as the perceived quality of the system in the population it serves. The discussion of equity in the current WHO formulation intentionally omits access to care from the list of fundamental goals, arguing that it is a latent aspect of the others, and hence an instrumental goal (Murray \& Frenk 2000). As the fundamental goals for performance of health systems are scrutinized further, however, the role of accessibility as a key aspect of equity will need to be made more explicit. Without access to services, equity in financing is essentially an irrelevant consideration.

Complementing needs to evaluate the performance of health systems, as WHO has begun doing, other efforts are facilitating self-report. A global database of data on national mental health systems has been planned by a WHO collaborating centre at the Institute of Psychiatry in London. It aims to provide information ultimately to be available on the World Wide Web for comparison and as a stimulus for creative policy. The country profiles will characterize the mental health of the population, factors that influence mental health, clinical and social services for treating mental illness, details of national mental health policies, and 
other relevant social programmes that influence mental health. Country profiles will enable policymakers to see where they stand with respect to others, and the availability of this information both serves an advocacy function and provides examples that promote the development and implementation of innovative policy and programmes informed by a wide range of experience.

In addition to such efforts to develop mental health systems, other factors that cannot be monitored easily also influence their effectiveness. Relationships between the public sector and other concerned parties, such as non-governmental voluntary organizations and private profit-making health services of various kinds, are often complex and idiosyncratic. Some problems of health systems arise from entrenched practices that are unrelated to acknowledged plans. Black markets for health services, kickbacks for referrals, bribery, and other forms of corruption take their toll on many health systems of low- and middle-income countries. Health actions that support an appropriate professional standard and ensure appropriate oversight and regulation help to minimize practices within health systems that are inimical to their goals.

\section{Formulating priorities, policy, and programmes}

Characterizing the burden of mental illness, refining diagnostic concepts, planning epidemiological research, promoting mental health systems, and evaluating their performance are cross-cutting tasks that constitute core functions of an international mental health system. WHO, the World Psychiatric Association, the World Federation for Mental Health, the U.S. National Institute of Mental Health (NIMH), the Royal College of Psychiatry, and other agencies concerned with international mental health also specify priorities and support programmes of various kinds. In addition to problem-focussed programmes, such as suicide 
prevention, stigma reduction, and attention to designated neuropsychiatric conditions, WHO has also encouraged the development of various models for community psychiatry that are responsive to the particular needs of rural areas and the needs of low- and middle-income countries. Motivated also by the World Mental Health Report, WHO established the Nations for Mental Health Programme in 1996 to stimulate and support a series of innovative community-based projects to improve mental health for underserved populations.

Other activities in the Department of Mental Health at WHO target five designated neuropsychiatric problems, including depression (which figures so prominently in burden of disease studies), dementia, mental retardation, schizophrenia, and epilepsy. International research on common mental disorders among patients in primary care supports programmes by clarifying the relationship between the specific nature of mental illness burden, help seeking, and needs for clinical training (Üstün and Sartorius 1995). WHO and other international agencies are also examining the range of traumatic stress reactions to determine whether and how informed professional responses to natural and man-made disasters may minimize long-range adverse impacts on mental health. Mental health programme activities are closely linked with efforts to counter substance abuse, and these links have been strengthened further by an administrative reorganization at WHO in the first quarter of the year 2000, combining mental health and substance abuse prevention activities in a single Department of Mental Health and Substance Dependence.

Stigma reduction is a key component of efforts to minimize the hidden social burden of mental illness. In addition to reducing suffering from stigma, these efforts also counter psychological defence mechanisms of minimization and denial fostered by stigma, which discourage appropriate help seeking for mental health problems, even when services are available (Wahl 1999). The World Federation of Mental Health, the World Psychiatric 
Association, the Royal College of Psychiatry in the United Kingdom, and NIMH are all deeply involved in population-based programmes to reduce the stigma of mental illness (Crisp 2000). Although some notions of stigma are widespread, specific meanings and implications may vary, and approaches to deal with it, targeting the general public and health care providers, are complex (Byrne 2000). With an inadequate understanding of the phenomenon, interventions designed to help may actually make matters worse (Yamey 1999); research is needed to inform stigma reduction programmes about relevant local concepts, formulate effective intervention strategies, assess baseline stigma, and evaluate the impact of these intervention programmes (Crisp et al. 2000).

\section{Balancing core and supportive functions}

WHO has been most active in addressing the core functions of the international mental health agenda, and WHO's Nations for Mental health Programme also performs a supportive function by assisting local projects in low- and middle-income countries. With the recent appointment of mental health advisors, the World Bank has also begun to engage in a supportive role for mental health, but thus far by considering aspects of mental health only as they apply to the Bank's own development projects. It does not support designated mental health projects, as the Nations project is doing. The Bank's recent plans to support epidemiological studies of psychiatric morbidity may also involve it in core mental health functions.

These developments suggest that the typical division of labour among international health agencies, associating WHO with core functions and the World Bank with supportive functions (Jamison et al. 1998), does not strictly hold for mental health. These ambiguities may reflect the newness of the Bank's involvement, but they raise questions about how the World 
Bank will operate in the field of mental health and how effective its involvement will be. What are the implications of the diffusion of responsibilities for core mental health functions? Will involvement of another agency in the core mental health functions stimulate creative rethinking of the agenda or a duplication and confusion of efforts? Will needed support for innovative mental health programmes be forthcoming from the World Bank? How will the core and supportive functions of these two key agencies be coordinated?

Keeping in mind the essential functions and changing features of the global mental health system, and open questions about its further development, we turn our attention to the history and current national mental health policy in India. As the focus shifts from global to national levels of policymaking, the discussion invites consideration and critical reflection on their respective roles.

\section{National focus: mental health in India}

Mental health problems in India affect approximately 10 to 20 per 1,000 of population, and approximately 10 million people in the country are suffering from serious mental illness. Taking into account common mental disorders, such as depression, anxiety, and somatoform (psychosomatic) disorders, the prevalence is 2 to 3 times higher. Over the range of health priorities, mental health has been a neglected issue; failure to appreciate the nature of mental illness and the fact that much of it is treatable have contributed to this neglect. In recent years, however, awareness of the prevalence, as well as the suffering and disability caused by mental disorders, has increased, and policymakers have begun to respond to the need for effective mental health services.

India has been an active collaborator in cross-national mental health research. It has participated in the major cross-national studies of mental disorders, beginning with the IPSS, 
and international activity in psychiatric epidemiology has also motivated national studies. A review of the development of mental health policy and services in India indicates how historically, international trends have influenced national policy. Conditions are now improving in mental hospitals, though there is still much to do in that regard. After independence, decentralized planning slowly began to provide alternatives to the large isolated institutions that segregate people with mental illness, encouraging development of general hospital psychiatry units, community psychiatry, and more recently district mental health planning. Recognizing the importance of illness prevention and mental health promotion as a component of mental health policy is an even more recent development.

\section{[Photograph 1. World Health Organization, Southeast Asia Regional Office (WHO/SEARO), New Delhi]}

These trends reflect the greater consideration and increasing influence of local conditions in communities, health services in a complex public-private mix, and featuers of clinical practice. A more self-confident national policy and less intrusive global policy make it possible to achieve a more balanced approach to mental health, better informed by an appropriate mix of global and local experience and data. Advocacy to ensure that mental health is not lost on the crowded agenda of development activities and other national priorities.

\section{Historical background}

During the colonial period, before India achieved independence from Great Britain in 1947, a number of "mad houses" and so-called lunatic asylums had been built in different parts of the country. These asylums were for the most part modelled after similar institutions in 
Britain and elsewhere in Europe, and they functioned along similar lines. The Indian Lunacy Act of 1912 specified guidelines for the management of these mental asylums, including procedures for admission and standards of care. Changes that were transforming the care of the mentally ill in Britain in the first quarter of the $20^{\text {th }}$ century also affected British India, and as part of an effort to promote humane and professional treatment, the lunatic asylums were re-christened mental hospitals in 1925. A significant substantive measure introduced with this change transferred control of mental hospitals from prison authorities to medically trained personnel. The mandate emphasizing incarceration of the mentally ill to protect society changed to reflect a reorientation of values emphasizing treatment and compassion.

As the government prepared for independence and self-rule, a health infrastructure was developed, and a high-profile committee under the chairmanship of Sir Joseph Bhore was appointed to formulate a plan for independent India to develop health services, which at the time of the report were grossly inadequate. The only psychiatric services were in mental hospitals, which numbered 19 with a bed strength of about 10,000. All of these were designed for the detention and custody of persons with mental disorders, but with scant regard for the care and treatment of these people as patients. The Bhore Committee recommended drafting a new mental health act to replace the Indian Lunacy Act of 1912, establishing new mental hospitals, and creating training facilities for mental health professionals.

After independence, planning for the health sector, as for many other aspects of development, was included among the responsibilities of the Planning Commission. Its fiveyear plans were responsible for developing clinical services and overall health policy. Scrutiny of these planning documents and analysis of funding allocations over the sequence of five-year plans from the 1950s show the absence of any clear-cut national policy for mental health. 
During this period health priorities emphasized control of communicable diseases—such as malaria, tuberculosis, and leprosy — and control of population growth through family planning.

\section{More mental hospitals}

Until the 1960s most mental health services in India remained primarily in mental hospitals. The first two decades after independence, following recommendations of the Bhore report, brought construction of many new mental hospitals in different parts of the country. This construction included mental hospitals in Amritsar in 1947, Hyderabad in 1953, Jaipur in 1954, Srinagar in 1958, Panaji (Goa) in 1959, and others. The last in this wave of construction was opened in Delhi in 1966. Today there are more than 40 mental hospitals of varying sizes throughout the country with a combined bed strength of about 20,000. Imbalances, however, are notable; some states, such as Maharashtra and Kerala, have three or more mental hospitals, but other states do not have even one. Overcrowding, a large proportion of chronic, long-stay patients who cannot easily be discharged, poor funding, inadequate facilities for rehabilitation of patients, and lack of adequately trained and motivated staff have continued to plague many mental hospitals. These factors contribute to deficient services, inadequate facilities, and the poor quality of care, which in turn contribute to persisting stigmatization of mental disorders.

\section{[Photograph 2. Central Institute of Psychiatry, Ranchi, Bihar]}

Various factors in recent decades have brought major changes in many of the country's mental hospitals. A series of media exposés publicizing the poor conditions and scandalous plight of the patients in many of these institutions elicited a public outcry and stimulated hospital reforms. Although attention to human rights in global mental health policy 
did not play a substantial role, the media in India focussed attention on the rights of the mentally ill and inappropriate placement of mentally ill persons in jails, especially in the states of West Bengal and Assam. Concerned citizens, social activists and progressive lawyers filed public interest writ petitions in various courts in different parts of the country, including the Supreme Court of India. These resulted in the establishment of commissions of inquiry, which brought about momentous interventions by the Supreme Court, resulting in a substantial increase in funding and improvement in the conditions of many mental hospitals.

The mental hospital at Shahdara in Delhi, the nation's captial, has been upgraded as a result of court rulings, and other hospitals have benefited in Ranchi, Agra, Gwalior, and Tezpur. The Supreme Court also decreed that mentally ill persons may not be placed in jails. The archaic Indian Lunacy Act of 1912 — which had continued to govern admission, detention, treatment, and discharge from mental hospitals_-and interim legislation of 1977 were repealed and replaced by the new Mental Health Act of 1987. It was especially significant because of its emphasis on treatment and care, and this legislation included provisions for penalties to be imposed on substandard institutions (Sharma and Chadda 1996). Based on another provision of this Mental Health Act, a set of Central Mental Health Authority Rules were promulgated in 1990 by the Central Government to ensure its implementation.

As a result of publicity and public scrutiny, judicial review, new legislation, and professionalization of psychiatric practice, the character and style of operation of many mental hospitals began to change. No longer consisting solely of inpatient locked wards, many now have outpatient services for ambulatory care, follow-up for outpatients, and outpatient followup care for inpatients after discharge. Admission is typically time-limited, rather than long-term and indefinite, as had often been the case in the past. Open inpatient units have supplemented or replaced locked wards, and various rehabilitation services have also been established. 
Although many authorities, including the Director-General of WHO (Brundtland 2000), regard centralized hospital-based psychiatric institutions as an example of regressive policies, these hospitals with upgraded facilities are likely to remain an important component of mental health services in India, especially for the care of persons with more severely disabling disorders. The National Human Rights Commission (NHRC) has recently completed a major quality assurance project involving all the mental hospitals in the country (NHRC 1999). The overall conditions and the quality of care may improve further in mental hospitals over the next few years as a result of this important initiative of the NHRC.

\section{Psychiatry units in general hospitals}

Motivated by developments in mental health care in Europe and North America, some of the earliest general hospital psychiatry units opened in India during the 1950s and 1960s. The pace accelerated considerably, however, only in the 1980s and 1990s, as more of these units opened throughout the country. At present, the capitals of all states, many other large cites (especially in some of the more progressive states, such as Kerala, Maharashtra, and Tamil Nadu), and most of the hospitals in district headquarters have general hospital psychiatry units. The number of beds in each may vary considerably, from just a few to 30 or more, depending on the size of the hospitals where the psychiatry units are placed. Shorter periods of hospitalization, ongoing involvement of family members in the care of patients, formulation of required treatment plans, and attitudinal changes stimulated by the relocation of psychiatry units in the active general hospital setting have all contributed to greater acceptance of psychiatric services as a part of medical care, and they also contribute to reduced stigmatization of mental disorders. 


\section{National Mental Health Programme}

The Government of India launched a National Mental Health Programme (NMHP) in 1982. It outlined a number of objectives intended not only to fulfill service needs but to do so in a manner that was consistent with and mindful of national priorities for development, existing social structures, and cultural values. Stated aims included (1) ensuring the availability and accessibility of at least a minimum standard of mental health care to the most vulnerable and underprivileged sections of the population; (2) encouraging application of mental health knowledge in general health care and social development programmes; and (3) promoting community participation in the development of mental health services while also encouraging community self-help activities (Gandevia 1993, P. 149; Government of India [GOI] 1982, Pp. 9-13).

The strategy for achieving these goals required a decentralized policy that gave precedence to community-based programmes. A comprehensive approach emphasized the value of integrating mental health, general health, and development programmes, a strategy that was consistent with the ideology of comprehensive primary health care advanced in the Alma Ata conference of 1978. A broad interpretation of mental health objectives fit well with this concept, and NMHP came to be included in the vision embodied in the slogan, "health for all by the year 2000." It is also consistent with the integrated approach to health and development now advocated by the World Bank, as it endeavours to soften its public image (Abbasi 1999).

Recognizing the need to document the burden of mental illness and in some cases making use of expertise acquired in India from participation in WHO's cross-national psychiatric epidemiological studies, several field surveys were conducted in representative samples of rural and urban populations in various parts of the country (Reddy and 
Chandrashekar 1998). Prevalence rates for most mental disorders were found to be similar to those elsewhere in the world. Studies also revealed a staggering load of mental health problems that required attention in general health clinics; an estimated $20-25 \%$ of all consultations in primary health care appeared to result primarily from emotional problems (Channabasavanna et al. 1995). Even in the 1980s it was already clear that for the estimated magnitude of mental health needs, the government health services could not fulfill the requirements for treatment of even $10 \%$; furthermore, existing services were highly centralized and situated predominantly in urban areas, where they were not readily accessible to the bulk of the population (GOI 1982). Meeting these needs by training specialists was inconceivable, and it was clear that a workable solution required better integration of mental health services in primary care.

The Government of India's NMHP for integrating mental health into general health services has established 28 centres to implement the programme. It aimed to develop an approach through primary health care to provide needed mental health services throughout the country. Early initiatives arising from the NMHP included an ICMR (Indian Council of Medical Research) multi-centre project for training of primary care doctors in psychiatry (Shamsundar et al. 1989). Tools and plans were developed and tested for diagnosing common disorders and providing effective grassroots management of mental disorders. NMHP plans also made use of experience from earlier community mental health projects, which can be traced back to a community psychiatry programme outside of Baroda, established in the late 1960s with collaboration of WHO and the University of Edinburgh (S.D. Sharma, personal communication); the WHO-supported Raipur Rani project in Haryana state in North India established in the 1970s (Sartorius \& Harding 1983); and the community mental health and training centre in Sakalavara outside of Bangalore in Karnataka, South India. 


\section{[Photograph 3. Indian Council of Medical Research (ICMR), New Delhi]}

In an effort to translate national policy into a broad base of local programmes, the National Institute of Mental Health and Neuro Sciences (NIMHANS) was asked to formulate a model of community mental health for rural areas in the context of the NMHP, and it designed and implemented a programme in Bellary District in the north of Karnataka State. That model has also guided other community mental health programmes in Karnataka, in neighbouring states in the region (Andhra Pradesh and Tamil Nadu), and elsewhere in the country (Rajasthan and Assam). Another series of community mental health programmes for Northeastern India in the latter half of the 1980s was planned at the Central Institute of Psychiatry in Ranchi, Bihar. These programmes emphasized training doctors to identify and either treat or refer serious psychiatric problems, including psychosis and severe depression (GOI 1990). The district mental health plan initiated in 1996 under the NMHP aims to expand coverage to 22 districts in 20 states (R.S. Murthy, personal communication).

These community mental health programmes have also supported outreach services for case finding and treatment of people with major mental illnesses, which also included epilepsy and mental retardation. In addition, they emphasized training of trainers, which means that district-level doctors were provided with skills to train health workers at primary health centres responsible for community outreach. Training materials were developed to explain the concepts of mental illness, to help identify cases, and to guide treatment. Training activities have also included workshops for government health secretaries whose responsibilities include mental health policy, planning, and mobilization of community workers. The aim was for mental health also to become a part of various other health and development activities of both 
governmental and nongovernmental organizations and to be addressed in the schools, an agenda that some WHO officials characerize as "mainstreaming" mental health (Üstün 2000).

Although the NMHP espoused decentralized services and community programmes, clinical services conforming to the traditional mental health service structures remained the dominant component of the overall system. The plan strove for consistency with principles and values embodied in the banner of "health for all," and it recognized the need for community and participatory approaches to make the strategy locally acceptable. It also aimed to use available resources as efficiently as possible. Nevertheless, the NMHP proved difficult to implement. The bridges needed to link expertise in mental health (defined conservatively as specialty training in clinical psychiatry) and the skills required for community development work have not functioned adequately, and results of the NMHP in India have been disappointing. Failure to appreciate the complexity of the required tasks, difficulty imparting interdisciplinary skills to facilitate needed collaboration, and failure to sustain sufficient commitment and resources to translate the ideology into a programme that could be implemented consistently eventually brought disappointment in the wake of enthusiasm.

\section{Specialty programme support: Substance abuse and dependence}

Substance abuse has been recognized as a serious problem in India since the early 1980s. It is especially severe in the northeastern region and in the state of Manipur, where it accounts for high rates of HIV seropositivity from intravenous heroin use (Chowdhury 1994). Detoxification and treatment of substance abusers throughout the country is typically provided in psychiatric facilities, where they are available, conforming with the policy advocated by the Narcotic and Psychotropic Substances Act of 1985. In addition to specifying criminal statutes and penalties, this act mandated development of programmes to treat and rehabilitate 
substance abusers. The Ministry of Health has established treatment facilities and trained personnel to staff these so-called de-addiction services.

The Seventh (1985-90) and Eighth (1992-97) Five Year Plans included provisions for centres of excellence in the departments of psychiatry of 5 central and 2 state-level institutions, as well as 61 drug de-addiction centres in different medical colleges throughout the country. The United Nations International Drug Control Programme (UNDCP) supported training of more than a thousand psychiatrists and medical officers, and in some centres treatment of substance abuse was linked with activities of the national AIDS control programme. This has had an effect of increasing interactions among personnel concerned with health-related behavioural change in mental health and HIV/AIDS prevention programmes, and the infusion of funds and attention has upgraded psychiatric programme facilities at the designated centres. Needed epidemiological research, however, to guide and evaluate these programmes has been minimal.

\section{Non-governmental organizations and the private sector}

Major questions remain open about how to link the national agenda of the NMHP with local policy, how to make best use of scarce specialty resources, and how to design and implement innovative programmes. While the responsibility for planning resides with the government, non-governmental organizations also play an increasingly important role in the process (Pachauri 1994). For some innovations, the private sector and non-profit organizations enjoy a flexibility and ability to experiment with alternative approaches that are more difficult for the government bureaucracy to test and implement in a timely way. In recent years voluntary organizations have also begun to take an unprecedented interest in mental health. Some NGOs offer walk-in counselling services, and some have established rehabilitation 
centres (day care) and half-way homes for the more severely disabled mentally ill. Many NGOs have also become involved in programmes to deal with problems of substance abuse and dependence.

In a large country like India, with its population at the 1 billion mark, national policy has begun to recognize the value of the commitment and activities of NGOs. In some cases, where their work is closely linked to community development, they may be especially well placed to formulate strategies not only for treating but also preventing mental disorders and promoting mental health, contributing to a comprehensive public mental health agenda beyond curative services. Less encumbered by the constraints of a clinically oriented health service system, and without direct responsibility in the organizational structure of the government health and other ministries, many NGOs operate effectively. Cross-cutting programmes of NGOs are better able to deal with the social aspects of many issues related to mental health, such as gender, alcohol and other substance abuse, and mental retardation. Although government policy increasingly accepts a role for NGOs in development, not all are equally capable, and extensive proliferation complicates their interactions with the government and with each other. In the wake of structural adjustment policies of the World Bank and unpopular health sector reforms, the Bank's emphasis on the role of NGOs, and recent attention to the public-private mix, is the focus of another critique. The question is whether governments in low- and middle-income countries are abandoning their responsibilities for health to NGOs and the private sector.

An active private sector, however, already plays an important role in India's health system, both in urban and rural areas, but with distinctly different features in different regions of the country. In urban areas one may find practising psychiatrists; in rural areas practitioners with diverse backgrounds and minimal training also provide services for emotional and mental 
health problems. National policy has an important role to play to ensure effective collaboration between public and private health sectors in the public-private mix. WHO and other international agencies recognize the limitations of strategies for government health planning that ignore an active private sector.

In India, where the patterns of private practice vary so much, careful attention to local conditions must inform efforts to promote such collaboration in the public-private mix.

Because training and qualifications among practitioners vary widely, especially in rural areas, government planning must acknowledge and interact appropriately with practitioners lacking officially recognizable credentials. To make effective use of the resources of the medically pluralistic health system, health policymakers need to understand who the various providers are and how they practice, so that it becomes possible to distinguish resources from obstacles within the system, and to develop a framework and strategy to evaluate prospects for appropriate training of various practitioners who are already providing health services in communities. Corrupt practices among medically qualified doctors, such as kickbacks for referrals and fees charged by government doctors in their public clinics or illicit private practice, compromise the effectiveness of the system and efforts to plan for it. Recognizing the importance and complexity of health policy that involves the private sector, with its potential value and pitfalls, effective national policy requires innovation in constructing a public-private mix that is mindful of — rather than shirking—responsibilities for health policy.

\section{Research in mental health}

Since independence, research in India has in large measure conformed to the international mental health research agenda (Sharif 1993, p.354). In the first phase of mental health research during the period from 1947 to 1960, research topics were often 
psychologically oriented; phenomenological and epidemiological studies were lacking.

Subsequent research after 1960 focussed on psychiatric epidemiology, clinical

phenomenology, and therapeutics, as well as study of relevant social phenomena. In the period since 1972, however, and especially in the last decade, biological psychiatry has become especially prominent, and research has focussed on the study of particular disorders, consistent with similar priorities in Europe and North America.

Although clinicians widely acknowledge a need for a cultural focus on clinical patterns and problems that may limit the value of Euro-American textbooks as guidelines for psychiatric practice in India, cultural research studies have in fact been limited. Efforts to pursue it have mainly reflected the interests and initiative of determined researchers, rather than national policy. The traditional interests of cultural psychiatry, a minority subspecialty in international psychiatry, were previously represented in research on culture-bound syndromes (critically reviewed by Raguram 2000), with studies of koro (Chowdhury 1996) and the dhat syndrome (Raguram et al. 1994). Until recently, much needed research pursuing broader objectives of cultural psychiatry to support clinical practice and community psychiatry has been lacking (Murthy 2000). The culturally sensitive epidemiological study in southwest India by Carstairs and Kapur (1976) represented an exceptional effort to develop mainstream epidemiological research interests with a cultural orientation. More recently, a framework for cultural epidemiology has been derived in large measure from mental health research in India. It is based on research experience with a group of semi-structured interviews, known collectively as the EMIC, which provide an account of illness from an insider's point of view and have begun to redress the dearth of cultural studies (Weiss 1997). Thus far, such efforts have been motivated by local initiatives, rather than national or global policy. 


\section{Local focus: recent rural and urban mental health initiatives}

Despite efforts to implement community-based mental health programmes through the NMHP, more are needed to serve the $90 \%$ of the rural population who remain without access to services. Programmes for urban communities are also needed, recognizing the distinctive rural and urban contexts, problems, and resources. In this section we focus on local policy and mental health action with reference to experience from planning a mental health programme for the Sagar Island development block in the underserved rural Sundarban Delta, West Bengal, and experience establishing a mental health component of an ongoing primary health care programme in an urban slum of Mumbai. We consider the background and approach to mental health planning for these communities and experience from initial steps to implement these plans.

\section{Planning for rural mental health in the Sundarban Delta, West Bengal}

A community mental health programme in the Sundarban region of the South 24 Parganas District of West Bengal has recently been initiated. Beginning on Sagar Island, where no formal mental health services existed, planning has been motivated by a preliminary survey of psychiatric morbidity and deliberate self-harm that substantiated needs. Among cases of deliberate self-harm by poisoning brought for treatment to the Rudranagar rural hospital, 15 resulted in fatalities, corresponding to a rate of 9.7 per 100,000 for the Sagar Island population from suicide by poisoning at this clinic alone, which is about the same as the national rate for all suicides. Taking other suicides into account among people not treated in the rural hospital, these data indicate the seriousness of deliberate self-harm on the island. Requests for services from the community and the interest of clinical staff at the rural hospital who recognized the 
value of skills to manage mental health issues encountered in primary care also motivated plans to establish this mental health programme.

\section{[Photograph 4. Coastal landscape, Sagar Island, West Bengal]}

Sagar Island is rural community of 154,172 population (1991 census). It has poor telephone connections to the mainland, only several hours of electricity daily, and access to the mainland by ferry. Although somewhat remote, Sagar nevertheless has a better ferry service than most of the other islands of this delta region. Planning for the programme began with extensive collaboration and interaction with the local village councils (gram panchayats in the panchayati raj system of local government). To guide planning, research was developed in the community. It examined social, cultural, environmental, and economic aspects of life in three representative villages of the island, with particular attention to the stressors and supports of principal livelihood activities (agriculture and fishing), gender relations, use of alcohol and drugs, the role of clinicians and healers consulted for mental health problems, local concepts of emotional distress and mental disorders in the community, and clinical cultural study of patients coming for treatment of mental health problems in the rural hospital clinic. Regular contact with the Institute of Psychiatry, Calcutta, was organized to provide the training, clinical backup, and support at the health centre. Psychiatry outpatient clinics at the Rudranagar rural hospital with the Calcutta psychiatrists were established as a result of these links. Among patients who came for treatment, major depression was the most frequent diagnosis, followed by generalised seizures and schizophrenia-spectrum psychotic disorders (Table 4).

Aims and activities of the programme, however, are based on an approach to community mental health that is more comprehensive than establishment of occasional 
specialty clinics. Specific objectives are consistent with those of the NMHP, though formulated a little differently. They include (1) training clinical staff of the health centre to recognize serious mental disorders and provide treatment or make referrals. This has long been a priority of the NMHP and earlier community mental health programmes. (2) Training clinical staff to recognize and address the emotional, psychiatric, and social problems of patients coming for treatment of nonfatal deliberate self-harm. Such patients have typically been treated only for the medical complications of a suicidal event, such as insecticide poisoning, rather than attending to the social and emotional issues that led to self-harm. (3) Training clinical staff to identify and treat common mental health problems that often affect patients coming for treatment in primary care, recognizing the role of typical social contexts in which these problems arise. (4) Promoting and supporting ongoing interactions with community residents and leaders to promote awareness of mental health issues and services, and to enhance community supports and reduce associated stigma.

A survey of the extensive local health system on Sagar Island identified 8 allopathic doctors, 512 eclectic medical practitioners without recognized qualifications, more than 40 magico-religious healers, and an assorted group of more than 50 practitioners that included homeopaths, ayurvedic doctors, astrologers, and religious leaders (maulvis and imams) who are consulted for medical problems. Many of the practitioners that comprise this extensive health system were found to be far more involved in treating mental health-related problems in the course of their practice than anticipated. Research is under way to examine their approaches to a range of clinical conditions and to consider prospects for working with an appropriately selected group to provide training and promote referral. Cultural epidemiological research among patients and nonaffected residents is also guiding the development of community mental health activities on Sagar Island. 


\section{Planning for urban mental health in a Mumbai slum}

Urbanization has dramatically increased the population of urban slums, where 28 million people in India reside. These slums are characterized by a deteriorating physical environment and inadequate housing, sanitation, and water supply. Overcrowding, poverty, unemployment, and various social and environmental conditions that foster ill health and impose considerable stress are pervasive. In Mumbai (formerly Bombay) 60\% of the people live in slums, and the number is rapidly increasing from both inward migration (the major factor) and internal growth. A mental health programme has been developed in the Malavani slum, which provides an example of a programme designed and developed to meet specific local needs of low-income urban residents.

\section{Malavani community}

The Malavani community was established in July 1975 by Sanjay Gandhi, son of Prime Minister Indira Gandhi, who had declared a political emergency at that time. It was originally populated by homeless people from central Bombay who were moved to this site, $35-40 \mathrm{~km}$ from the city centre. Subsequently, it continued to grow with inward migration from all over the country, and consistent with the communal status of the original population, the majority remain predominantly Muslim (60\%), and the rest are mostly Hindu (38\%). The quality of housing in this community of 120,000 people varies considerably, ranging from rough-hewn shacks to stable concrete structures. Most have poor ventilation, lighting, water supply, and sanitary facilities. Although municipal toilets are available for some of the people, open defecation is a common practice.

To support health services in low-income communities like Malavani, the Greater Mumbai Municipal Corporation requires teaching hospitals to assist by providing health 
services in designated slum communities. To meet this requirement, in 1977 the Department of Preventive and Social Medicine at KEM Hospital (a respected municipal hospital and the academic teaching hospital for the Seth GS Medical College) began to manage the primary health centre, which is the principle source of health care for the community. Additional local health services include a smaller municipal dispensary and various private practitioners, many with unrecognized qualifications. Most of these health care providers deal mainly with common medical problems in outpatient clinics. The Malavani primary health centre (PHC) also has special programmes for tuberculosis and for child health, which are supported by international agencies. The mix of preventive, promotive, and curative activities includes immunizations, health education, antenatal, and postnatal services. In addition to the general health services it provides, the PHC is a field site for teaching and training students and clinicians from KEM Hospital.

\section{[Photograph 5. Malvani slum community and background of metropolitan Mumbai skyline]}

\section{Mental health services}

Mental health services were established in 1993 just after communal riots and ethnic violence seriously disrupted Bombay in 1993. Not surprisingly, in view of the Hindu-Muslim mix in the community, the disturbances during that period had a serious impact. The need for emotional support for victims of violence motivated involvement of the Psychiatry Department, which previously had not provided services in the PHC. Initially, it was thought that this intervention would be short-term, and psychiatric services would be temporary. Working in the community and interacting with clinicians, however, psychiatric personnel 
identified common mental disorders, such as depression, anxiety, and somatic symptoms rooted in emotional problems among patients coming for medical treatment. As a result of interactions with patients and clinic staff, the need for sustained mental health services became apparent, and a psychiatric clinic was established in 1995 as a component of the PHC. Aims were to provide clinical services and promote community awareness through mental health education. Primary health clinicians, nursing staff, and social workers were trained in a workshop at the outset so they could identify mental health problems and refer patients to psychiatric personnel on site. Later, workshops were organized to impart similar skills to community health workers.

A survey in 1995 showed that $27.9 \%$ of patients over 18 years of age in the urban health centre suffered from emotional distress and symptoms serious enough to be considered psychiatric problems. Among them depressive disorders accounted for 32\%, and $37 \%$ had anxiety, somatoform, or adjustment disorders. Alcohol and drug-related problems affected 20\%, and psychosis 4\%. Annual records for 1996 are summarized in table 5, showing the frequency of symptoms among patients referred to the psychiatric clinic of the PHC. Essential drugs for treating psychiatric disorders have been made available in the community. These include antipsychotics (chlorpromazine and trifluoperazine), an antidepressant (imipramine), and an anxiolytic (diazepam). From the outset, the clinic has been run by postgraduate medical trainees, social workers, and psychologists, with one consultant available for backup. It has endeavoured to integrate with other activities of the health centre, maintaining a focus on the broader needs of patients, rather than attempting to serve as a specialty clinic. Objectives included early identification and treatment of mental health problems through interactions with colleagues and other clinic staff at various levels to ensure they were aware of the available mental health services. 
The community has been especially interested in services to deal with behavioural problems of children, and they also wanted help with problems arising from substance abuse and dependence. As prevention and treatment for addictions became priorities, a special programme was developed with financial support of WHO provided through the Ministry of Health, Government of India, to promote awareness of drug problems and existing services.

Experience in the community indicates some of the innovative ways that residents have tried to deal with these problems on their own. The following anecdote is one of many examples. A group of young women, all in their early 20s, organized themselves as a result of a common problem. They had become frustrated by the inactivity of their men, who were spending their days idly lying about without interest in working or looking for work, preferring instead to smoke cannabis (ganja) continually. Left with the hardship of full responsibilities for maintaining the households and supporting their children, these women decided something must be done. They approached the community mental health team, which they knew to be concerned with drug problems, requesting immediate help. Told that help would require motivation and would take some time, the women took it upon themselves to find a solution. Although they were illiterate, the women asked a schoolboy, a child of one of them, to write a letter on official looking paper, stating that the police would be raiding the community and arresting the men for smoking ganja and harassing their women. The women then stayed away for a night in a local building under construction. When they returned in the morning, the men were repentant and some have renounced their smoking, successfully remaining abstinent from cannabis for the past ten months. Even among the men who are working, however, alcohol appears to have replaced ganja.

Community awareness activities have become an essential component of the mental health programme. These activities include lectures by social workers and nursing staff. 
Community participation has been promoted by involving leaders of the local women's and youth groups, and other organizations. Community action facilitators, some of whom are illiterate, have been selected and paid to work in the community to promote awareness of mental health problems and guide people to services. They arrange exhibitions and street plays in various parts of Malavani. Personnel from local NGOs have also been trained and take part in preventive and promotive activities.

As information about the mental health programme spread in the community and both laypersons and professional clinic staff became aware of how mental health services might be useful, the number of users attending the clinic increased substantially. In the years from 1994 (when psychiatric services were first introduced) to 1997, the number of patients coming for treatment increased threefold (Table 6). Useful suggestions for implementing and improving mental health and drug awareness activities, such as a school-based programme and home visits to improve follow-up clinical care, came from focus groups in the community. In addition to the community involvement and the service component in the development of the Malvani community mental health programme, it has also become a site for training in community mental health. The combination of clinical services, clinic staff development, community participation, and mental health awareness activities indicate the nature of the mix that contributes to an urban mental health programme.

\section{Conclusion}

This review of essential functions of international mental health agencies, India's national mental health system, and local approaches to rural and urban mental health policy in communities of West Bengal and Mumbai indicate how each level of policy and action relates to the others. Core functions of international agencies serve cross-cutting mental health 
interests that justify and inform activities at national and local levels. Local programmes are concerned with and must be attentive to the particular needs and interests of the communities they serve. They require the support of global and national policy for resources and for the conceptual tools to formulate and implement appropriate strategies to meet local needs. Attention to core functions-particularly epidemiological studies that specify and monitor the mental health status of populations—-have been and remain a priority (Kessler 2000). Other essential functions need strengthening, however, particularly core functions that may guide mental health actions after the magnitude of the burden has been established. Resources and innovative approaches to programme support are needed in the context of supportive functions to develop models and to assist where national and local resources are inadequate, and where evidence suggests inputs may lead to the development of sustainable programmes. The case study for India indicates how national programmes have attempted to meet responsibilities for the health and welfare of their populations. As the portal through which global and local interests, ideas, and policies formally interact, national policy in India—based on ideals of community health, decentralization, and the priority of local comprehensive health actions-influenced development of the health-for-all health strategy. This global policy in turn influenced development of the NMHP and various other efforts to develop community health. Our review has also considered shortcomings in the efforts to translate this strategy into policy and difficulties implementing that policy in effective mental health actions.

India was chosen as a national case study in part because it has a relatively welldeveloped mental health system. For the same reason it is not truly representative, inasmuch as other countries of the region do not. Over the past several decades Sri Lanka, for example, has often been cited as an exemplary low-income country that was able to achieve equitable access to general health services and improve the general health status of its population. It has 
demonstrated its capacity to implement and benefit from well-considered health policy. Mental health, however, has not fared well. The country lacks any national mental health plan, and improvements in general health status contrast sharply with increasing suicide rates that in recent years have reached levels among the highest in the world. Although WHO's Nations for Mental Health Programme supports local programmes, neither it nor other international agencies support the development of national mental health programmes, which are needed to generalize and sustain local programmes. In selected countries with a combination of extensive needs, demonstrated ability to benefit from implementing related health policy, and availability of professional expertise to facilitate partnerships for development of mental health policy, attention to the supportive functions of global agencies holds substantial potential for contributing directly to mental health, not only in these countries but elsewhere as well. Locally adaptable models informed by appropriate research strategies are needed. Better coordination of essential functions among global agencies is required to reduce fragmentation, ensure balance, and enhance synergy in the three levels of policy.

Formulating objectives and mutually responsive plans at each level of mental health policymaking is a critical and difficult task. International priorities must be sensitive to a wide range of national interests, which in turn must consider diverse local experiences. If not, then policy imposed from a higher level that appears arbitrary or irrelevant is more likely to result in frustration than effective action. A former Director-General of the Indian Council of Medical Research, V. Ramalingaswami (1986), invoked the art of the possible as a metaphor and ideal for international health. The overview, examples, opportunities, and pitfalls considered here show that as policymakers strive to achieve an effective mental health policy, they must proceed thoughtfully to ensure that the right mix of global and local orientations expands the domain of the possible in the practice of that art. 


\section{Acknowledgement}

Discussion, comments, and information contributing to this paper from Professors J.

Ramakrishna, S.D. Sharma, and R.S. Murthy are appreciated. Support to the first author from the Swiss National Science Foundation, Grant \#32-51068.97, Cultural Research for Mental Health, is gratefully acknowledged. 


\section{Reference List}

Abbasi, Kamran. (1999). The World Bank and world health: Changing sides. BMJ 318:865869.

AbouZahr, C.; Vaughan, J.P. (2000). Assessing the burden of sexual and reproductive illhealth: questions regarding the use of disability-adjusted life years. Bull WHO 78(5):655-666.

Baru, Rama, \& Jessani, Amar. (2000). The role of the World Bank in international health: renewed commitment and partnership. Soc Sci Med 50:183-184.

Brundtland, Gro Harlem. (2000). Mental health in the $21^{\text {st }}$ century (Editorial). Bull WHO 78(4):411.

Byrne, P. (2000). Stigma of mental illness and ways of diminishing it. Advances in Psychiatric Treatment 6:65-72.

Carstairs, G.M., \& Kapur, R.L. (1976). The great universe of Kota: Stress, change and mental disorder in an Indian village. Berkeley: University of California Press.

Channabasavanna, S.M., Sriram, T.G., \& Kumar, K. (1995). Results from the Bangalore centre. In: Üstün, T.B., \& Sartorius, N. (Eds.), Mental Illness in General Health Care: An Internatioal Study. Chichester: John Wiley \& Sons; Pp. 79-97.

Chowdhury, A.N. (1996). The definition and classification of koro. Culture, Medicine, and Psychiatry 20:41-65.

Chowdhury, A.N. (1994). Heroin and HIV epidemic in India: a note on North-Eastern states. Journal of Indian Anthropological Society 29:287-302.

Crisp, A. (2000). Changing minds: every family in the land. Psychiatric Bulletin 24:267-268.

Crisp, A., Gelder, M.G., Rix, S., Meltzer, H.I., Rowlands, O.J. (2000). Stigmatisation of people with mental illness. Br J Psychiatry 177:4-7 
Desjarlais, R., Eisenberg, L., Good, B., Kleinman, A. (1995). World mental health: problems and priorities in low-income countries. New York: Oxford University Press.

Feachem, Richard G.A. (2000). Health systems: more evidence, more debate (Editorial). Bull WHO 78(6):715.

Gandevia, Katy Y. (1993). Community mental helath : a historical overview of past and present interventions. Ch. 8, pp. 144-171, In: Mane, Purnima; Gandevia, Katy Y. (Eds.), Mental Health in India: Issues and Concerns. Bombay: Tata Institute of Social Sciences.

Government of India. Directorate General of Health Services. (1990). National Mental Health Programme-A Progress Report 1982-1990. New Delhi: DGHS, Nirman Bhavan, Government of India.

Government of India, Director-General of Health Services. (1982). National Mental Health Programme for India, A Report. New Delhi: Ministry of Health and Family Welfare, Government of India.

Jamison, Dean T.; Frenk, Julio; Knaul, Felicia. (1998). Internaitonal collective action in health: objectives, functions, and rationale. Lancet 351:514-517.

Jenkins, Rachel. (1997). Reducing the burden of mental illness (Editorial). Lancet 349:1340.

Kawabata, Kei. (2000). A new look at health systems (Editorial). Bull WHO 78(6):716.

Kessler, Ronald C. (2000). Psychiatric epidemiology: selected recent advances and future directions. Bull WHO 78(4):464-474.

Lee, Sing. (1996). Cultures in psychiatric nosology: the CCMD-2-R and international classification of mental disorders. Culture, Medicine, and Psychiatry 20(4):421-472.

Lomas, J. (1998). Social capital and health: implications for public health and epidemiology. Soc Sci Med 47(9):1181-1188. 
McMichael, A.J.; Beaglehole, R. (2000). The changing global context of public health. Lancet 356:495-499.

Mosley, W.H. (1988). Is there a middle way? Categorical programs for PHC. Soc Sci Med 26(9):907-908.

Murray, Christopher J.L.; Frenk, Julio. (2000). A framework for assessing the performance of health systems. Bull WHO 78(6): 717-731.

Murray, Christopher J.L; Lopez, Alan D. (1997). Regional patterns of disability-free life expectancy and disability-adjusted life expectancy: Global Burden of Disease Study. Lancet 349:1347-1352.

Murray, C.J.L., Lopez, A.D. (1996a). The global burden of disease. Cambridge, MA: Harvard University Press. Global burden of disease and injury series. Vol. I.

Murray, Christopher J.L; Lopez, Alan D. (1996b). Evidence-based health policy—Lessons from the Global Burden of Disease Study. Science 274:740-743.

Murthy, R.S. (2000). Community resources for mental health care in India. Epidemiologia e Psichiatria Sociale, 9(2):89-92.

National Human Rights Commissin India (NHRC). (1999). Quality Assurance in Mental Health. New Delhi: NHRC.

Pachauri, Saroj (Ed). (1994). Reaching India's Poor: Non-governmental Approaches to Community Health. New Delhi: Sage Publications.

Raguram, R. (2000). Culture-bound syndromes. In: Yilmaz, A.T.; Weiss, M.G.; RiecherRössler, A. (Eds.). Cultural Psychiatry: Euro-International Perspectives. Basel: Karger.

Raguram, R.; Jadhav, S.S.; Weiss, M.G. (1994). Historical perspective of dhat syndrome. NIMHANS Journal. NIMHANS Journal 1994; 12(2):117-124. 
Ramalingaswami, V. (1986). The art of the possible. Soc Sci Med 22(11):1097-1103.

Reddy, M.V.; Chandrashekar, C.R. (1998). Prevalence of mental ahd behavioural disorders in India: A meta-analysis. Indian Journal of Psychiatry 40:149-157.

Saltman, Richard B.; Ferroussier-Davis, Odile. (2000). The concept of stewardship in health policy. Bull WHO 78(6):732-739.

Sartorius, N., \& Harding, T.W. (1983). The WHO collaborative study on strategies for extending mental health care, I: The genesis of the study. American Journal of Psychiatry 140(11):1470-1473.

Sayers, B.M., \& Fliedner, T.M. (1997). The critique of DALYs: a counter-reply. Bull WHO 75(4):383-384.

Shah, A., \& Jenkins, R. (2000). Mental health economic studies from developing countries reviewed in the context of those from developed countries. Acta Psychiatrica Scandinavica 101(2):87-103.

Shamsundar, C., John, J., Reddy, P.R., Verghese, A., Chandramouli, Isaac, M.K., \& Kaliaperumal, V. (1989). Training general practitioners in psychiatry-An ICMR multicentre study. Indian Journal of Psychiatry 31:271-279.

Shariff, I.A. (1993). Mental health services in India: a contemporary and futuristic view. Ch 19, Pp. 346-366, In: Mane, Purnima; Gandevia, Katy Y. (Eds.), Mental Health in India: Issues and Concerns. Bombay: Tata Institute of Social Sciences.

Sharma, Shridhar; Chadda, Rakesh Kumar. (1996). Mental Hospitals in India: Current Status and Role in Mental Health Care. Delhi: Institute of Human Behaviour and Allied Sciences.

Tansella, Michele. (2000). Making mental health services work at the primary level. Bull WHO 78:501-502. 
Üstün, T.B. (2000). Mainstreaming mental health (Editorial). Bull WHO 78(4):412.

Üstün, T.B. (1999). The global burden of mental disorders. Am J Public Health 89:1315-1318. Üstün, T.B., Sartorius, N. (1995). Mental Illness in General Health Care: An International Study. Chichester: John Wiley and Sons.

Wahl, O.F. (1999). Mental health consumers' experience of stigma. Schizophrenia Bulletin 25(3):467-478.

Walker, R. Dale. (1996). Mental health and disability. Science 274:1593-1597.

Weiss, Mitchell G.; Cohen, Alex; Eisenberg, Leon. (2000). Mental health. Chapter 7. In: Merson, Michael; Black, Bob; Mills, Anne (Eds.), Introduction to International Health. Gaithersberg, MD: Aspen Publishers.

Weiss, M.G. (2000). Psychiatric diagnosis and illness experience. In: AT Yilmaz, MG Weiss, A. Riecher-Rössler (Eds), Cultural Psychiatry: Euro-International Perspectives. Basel: Karger.

Weiss, M.G. (1997). Explanatory Model Interview Catalogue: Framework for comparative study of illness experience. Transcultural Psychiatry 34:235-263.

Wig, N.N. (2000). WHO and mental health—a view from developing counries. Bull WHO 78:502-503.

World Bank. (1993). World development report 1993. Investing in health. New York: Oxford University Press.

World Bank (2000). World development report 1999/2000. Entering the $21^{\text {st }}$ century: The changing development landscape. New York Oxford University Press.

World Health Organization. (1999a). World Health Report 1999-Making a Difference. Geneva: World Health Organization. 
World Health Organization (1999b). Figures and facts about suicide. Department of Mental Health. Geneva: World Health Organization.

World Health Organization. (2000a). The World Health Report 2000—Health Systems: Improving Performance. Geneva: World Health Organization.

World Health Organization. (2000b). Setting the WHO agenda for mental health. Bull WHO 78:500.

WHO International Consortium in Psychiatric Epidemiology. (2000). Cross-national comparisons of the prevalences and correlates of mental disorders. Bull WHO $78(4): 413-426$.

Yamey, G. (1999). Young less tolerant of mentally ill than the old. Lancet 319, 1092. 


\section{Tables and Figures}

Table 1. Burden of Neuropsychiatric Disorders and Intentional Self-injury in Countries Grouped by Adult Mortality Stratum

Table 2. Per Capita Burden of Neuropsychiatric Disorders and Intentional Selfinjury in Countries Grouped by Adult Mortality Stratum

Table 3. Deaths by Intentional Self-Injury (Suicide), Estimates for 1999

Table 4. Psychiatric and seizure disorders among patients attending Sundarban psychiatric clinics from June 1998 to September 2000.

Table 5. Frequency of Symptoms in the Malavani PHC from Audit of Clinic Records, 1996

Table 6. Attendance at Malavani Mental Health Clinic since Established in 1994

Figure 1. Global Burden of Disease with Specified Neuropsychiatric Disorders and Intentional Self-Injury, Estimate for 1999 
Table 1. Burden of Neuropsychiatric Disorders and Intentional Self-injury in Countries Grouped by Adult Mortality Stratum*

\begin{tabular}{|c|c|c|c|c|c|c|c|c|}
\hline \multirow{3}{*}{$\begin{array}{l}\text { Mental health } \\
\text { problem }\end{array}$} & \multicolumn{8}{|c|}{ Adult Mortality Stratum } \\
\hline & \multicolumn{2}{|c|}{ Very low } & \multicolumn{2}{|c|}{ Low } & \multicolumn{2}{|c|}{ High } & \multicolumn{2}{|c|}{ Very high } \\
\hline & $\begin{array}{c}\% \\
\text { Total DALYs }\end{array}$ & $\begin{array}{c}\% \\
\text { Neuropsych } \\
\text { \& self-injury } \\
\text { DALYs }\end{array}$ & $\begin{array}{c}\% \\
\text { Total DALYs }\end{array}$ & $\begin{array}{c}\% \\
\text { Neuropsych } \\
\text { \& self-injury } \\
\text { DALYs }\end{array}$ & $\begin{array}{c}\% \\
\text { Total DALYs }\end{array}$ & $\begin{array}{c}\% \\
\text { Neuropsych } \\
\text { \& self-injury } \\
\text { DALYs }\end{array}$ & $\begin{array}{c}\% \\
\text { Total DALYs }\end{array}$ & $\begin{array}{c}\% \\
\text { Neuropsych } \\
\text { \& self-injury } \\
\text { DALYs }\end{array}$ \\
\hline Neuropsych Disorders ${ }^{* *}$ & 24.6 & 90.8 & 15.6 & 85.7 & 7.8 & 85.4 & 3.9 & 81.2 \\
\hline $\begin{array}{l}\text { Unipolar Major } \\
\text { Depression }\end{array}$ & 7.1 & 26.0 & 6.3 & 34.8 & 3.1 & 33.6 & 1.4 & 29.1 \\
\hline $\begin{array}{l}\text { Bipolar Affective } \\
\text { Disorder }\end{array}$ & 1.8 & 6.5 & 1.8 & 9.6 & 0.9 & 9.6 & 0.4 & 8.4 \\
\hline Psychoses & 2.2 & 8.2 & 1.1 & 6.2 & 0.7 & 7.3 & 0.1 & 2.9 \\
\hline Epilepsy & 0.5 & 2.0 & 0.6 & 3.5 & 0.5 & 5.2 & 0.5 & 9.8 \\
\hline Alcohol Dependence & 5.0 & 18.4 & 1.9 & 10.2 & 0.6 & 7.0 & 0.5 & 10.9 \\
\hline $\begin{array}{l}\text { Alzheimer \& other } \\
\text { Dementias }\end{array}$ & 3.4 & 12.4 & 0.8 & 4.6 & 0.4 & 4.3 & 0.1 & 1.9 \\
\hline Drug Dependence & 1.6 & 5.8 & 0.5 & 2.9 & 0.2 & 2.4 & 0.1 & 2.3 \\
\hline $\begin{array}{l}\text { Posttraumatic Stress } \\
\text { Disorder }\end{array}$ & 0.3 & 1.0 & 0.2 & 1.2 & 0.1 & 1.3 & 0.1 & 1.2 \\
\hline $\begin{array}{l}\text { Obsessive-Compulsive } \\
\text { Disorder }\end{array}$ & 1.5 & 5.6 & 1.2 & 6.6 & 0.6 & 6.8 & 0.3 & 6.0 \\
\hline Panic Disorder & 0.7 & 2.7 & 0.6 & 3.1 & 0.3 & 3.1 & 0.1 & 2.8 \\
\hline Intentional Self-injury & 2.5 & 9.2 & 2.6 & 14.3 & 1.3 & 14.6 & 0.9 & 18.8 \\
\hline
\end{tabular}

* Data compiled from World Health Organization, World Health Report 2000, Geneva, 2000; Annex table 4.

** Total for all disorders, including small unspecified component in WHO total, but not intentional self-injury; excludes multiple sclerosis and Parkinson disease. 
Table 2. Per Capita Burden of Neuropsychiatric Disorders and Intentional Self-injury in Countries Grouped by Adult Mortality Stratum*

\begin{tabular}{|lr|r|r|r|}
\cline { 2 - 5 } \multicolumn{1}{c|}{} & \multicolumn{4}{c|}{ Adult Mortality Stratum } \\
\cline { 2 - 5 } \multicolumn{1}{c|}{} & Very low & \multicolumn{1}{c|}{ Low } & \multicolumn{1}{c|}{ High } & Very high \\
\hline Population (000s) & 881,350 & $2,579,649$ & $2,170,544$ & 330,085 \\
\hline Mental health problem & \multicolumn{3}{c|}{ Per capita DALYs } \\
\hline Neuropsychiatric Disorders** & 28.7 & 26.5 & 24.6 & 25.6 \\
\hline \hline Unipolar Major Depression & 8.2 & 10.8 & 9.7 & 9.2 \\
\hline Bipolar Affective Disorder & 2.1 & 3.0 & 2.8 & 2.6 \\
\hline Psychoses & 2.6 & 1.9 & 2.1 & 0.9 \\
\hline Epilepsy & 0.6 & 1.1 & 1.5 & 3.1 \\
\hline Alcohol Dependence & 5.8 & 3.1 & 2.0 & 3.4 \\
\hline Alzheimer \& other Dementias & 3.9 & 1.4 & 1.2 & 0.6 \\
\hline Drug Dependence & 1.8 & 0.9 & 0.7 & 0.7 \\
\hline Posttraumatic Stress Disorder & 0.3 & 0.4 & 0.4 & 0.4 \\
\hline Obsessive-Compulsive Disorder & 1.8 & 2.0 & 2.0 & 1.9 \\
\hline Panic Disorder & 0.8 & 1.0 & 0.9 & 0.9 \\
\hline Intentional Self-injury & 2.9 & 4.4 & 4.2 & 5.9 \\
\hline
\end{tabular}

* Data compiled from World Health Organization, World Health Report 2000, Geneva, 2000; Annex table 4.

** Total for all disorders, including small unspecified component in WHO total, but not intentional self-injury; excludes multiple sclerosis and Parkinson disease. 
Table 3. Deaths by Intentional Self-Injury (Suicide), Estimates for 1999*

\begin{tabular}{|l|r|r|r|r|}
\hline Adult Mortality Stratum & \multicolumn{1}{|c|}{$\begin{array}{c}\text { Population } \\
\mathbf{( 0 0 0 )}\end{array}$} & $\begin{array}{c}\text { All Deaths } \\
\mathbf{( 0 0 0 )}\end{array}$ & $\begin{array}{c}\text { Suicide Rate } \\
\text { per 100,000 }\end{array}$ & $\begin{array}{c}\text { Percentage } \\
\text { Deaths by } \\
\text { Suicide }\end{array}$ \\
\hline Very low & 881,350 & 7,840 & 13.6 & 1.5 \\
\hline Low & $2,579,649$ & 18,332 & 17.3 & 2.4 \\
\hline \hline Combined very low and low & $3,460,999$ & 26,172 & 16.3 & 2.2 \\
\hline High & $2,170,544$ & 23,739 & 13.4 & 1.2 \\
\hline Very High & 330,085 & 6,055 & 11.1 & 0.6 \\
\hline \hline Combined high and very high & $2,500,628$ & 29,793 & 13.1 & 1.1 \\
\hline
\end{tabular}

* Data compiled from World Health Organization, World Health Report 2000, Geneva, 2000; Annex table 3. 
Table 4. Psychiatric and seizure disorders among patients attending Sundarban psychiatric clinics from June 1998 to September 2000.

\begin{tabular}{|l|r|r|r|r||r|r|}
\hline \multirow{2}{*}{ Clinical Diagnosis } & \multicolumn{2}{c|}{ Men (n=61) } & \multicolumn{2}{c||}{ Women (69) } & \multicolumn{2}{c|}{ Total (130) } \\
\cline { 2 - 8 } & $\mathbf{N}$ & \multicolumn{1}{c|}{$\%$} & $\mathbf{N}$ & \multicolumn{1}{c|}{$\%$} & $\mathbf{N}$ & $\%$ \\
\hline Major depressive disorder & 19 & $31.1 \%$ & 25 & $36.2 \%$ & 44 & $33.8 \%$ \\
\hline Generalised tonic-clonic seizures & 14 & $23.0 \%$ & 11 & $15.9 \%$ & 25 & $19.2 \%$ \\
\hline $\begin{array}{l}\text { Schizophrenia-spectrum psychotic } \\
\text { disorders }\end{array}$ & 13 & $21.3 \%$ & 9 & $13.0 \%$ & 22 & $16.9 \%$ \\
\hline Bipolar disorder, manic episode & 6 & $9.8 \%$ & 10 & $14.5 \%$ & 16 & $12.3 \%$ \\
\hline Mental retardation & 4 & $6.6 \%$ & 4 & $5.8 \%$ & 8 & $6.2 \%$ \\
\hline Generalised anxiety disorder & 3 & $4.9 \%$ & 3 & $4.3 \%$ & 6 & $4.6 \%$ \\
\hline Hysteria & 0 & $0.0 \%$ & 7 & $10.1 \%$ & 7 & $5.4 \%$ \\
\hline Obsessive-compulsive disorder & 2 & $3.3 \%$ & 0 & $0.0 \%$ & 2 & $1.5 \%$ \\
\hline
\end{tabular}


Table 5. Frequency of Symptoms in the Malavani PHC from Audit of Clinic Records, 1996 ( $N=217$ )

\begin{tabular}{|l|c|}
\hline \multicolumn{1}{|c|}{ Symptom } & $\begin{array}{c}\text { Frequency } \\
\text { (\%) }\end{array}$ \\
\hline Somatic complaints & 80 \\
\hline Fatigability & 52 \\
\hline Sleep disturbance & 40 \\
\hline Appetite disturbance & 57 \\
\hline Irritability & 20 \\
\hline Sadness & 32 \\
\hline Abnormal behaviour & 14 \\
\hline
\end{tabular}


Table 6. Attendance at Malavani Mental Health Clinic since Established in 1994

\begin{tabular}{|c|c|}
\hline \multicolumn{1}{|c|}{ Year } & \multicolumn{2}{|c|}{$\begin{array}{c}\text { Clinic } \\
\text { Attendance }\end{array}$} \\
\hline 1994 & 85 \\
\hline 1995 & 159 \\
\hline 1996 & 217 \\
\hline 1997 & 289 \\
\hline
\end{tabular}


Figure 1

\section{Global Burden of Disease with Specified}

\section{Neuropsychiatric Disorders \& Intentional Self-injury, Estimate for 1999*}

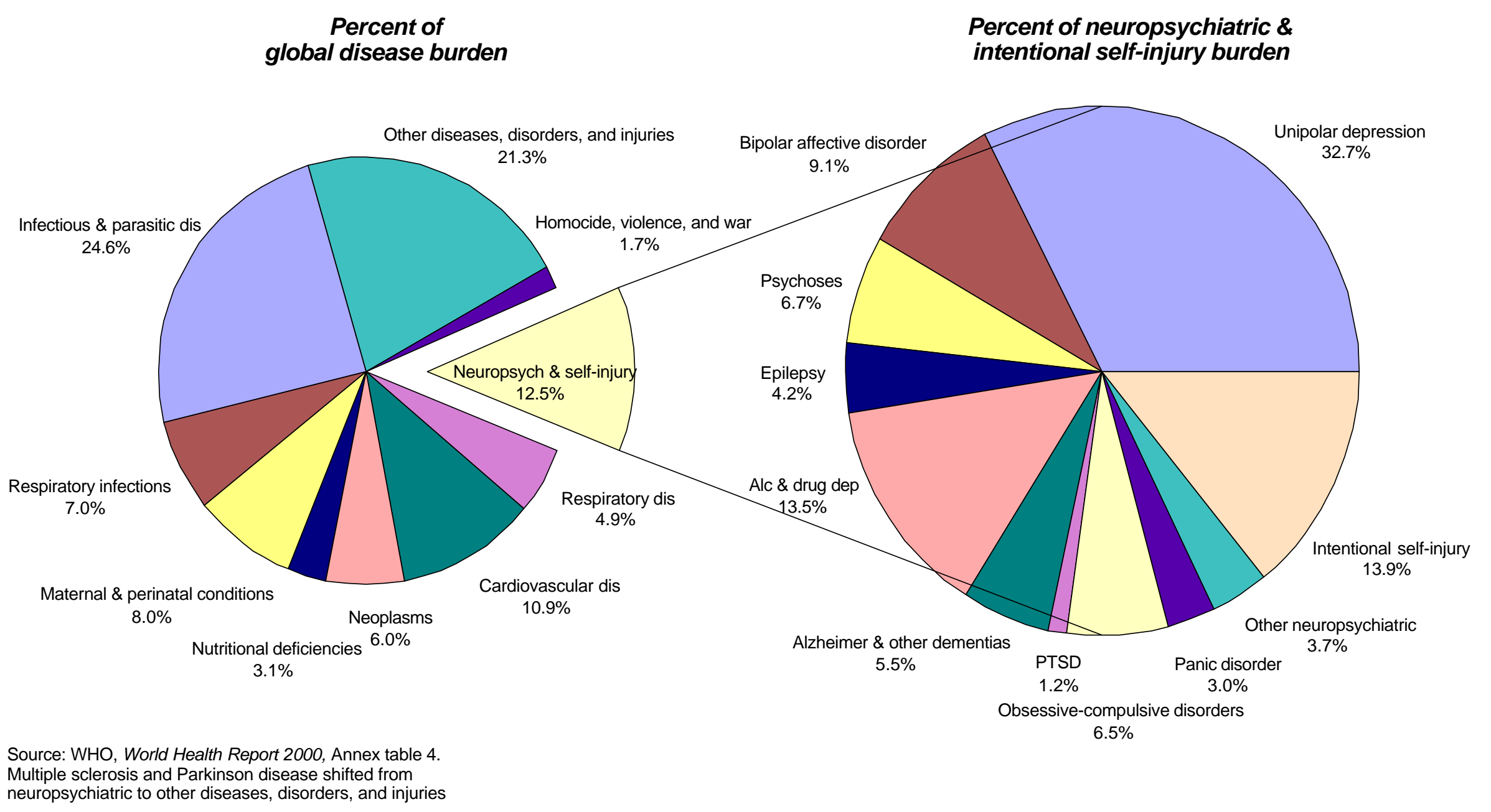




\section{Photographs}

1. World Health Organization, Southeast Asia Regional Office (WHO/SEARO), New Delhi

File: WHO-SEARO-Delhi.jpg

2. Central Institute of Psychiatry, Ranchi, Bihar

[Enclosed File: CIP2.jpg]

3. Indian Council of Medical Research (ICMR), New Delhi

[File: ICMRentrance.jpg]

4. Coastal landscape, Sagar Island, West Bengal

[File: SagarCoastal.JPG]

5. Malvani slum community and background of metropolitan Mumbai skyline [File: Malavani.jpg] 
1. World Health Organization, Southeast Asia Regional Office (WHO/SEARO), New Delhi

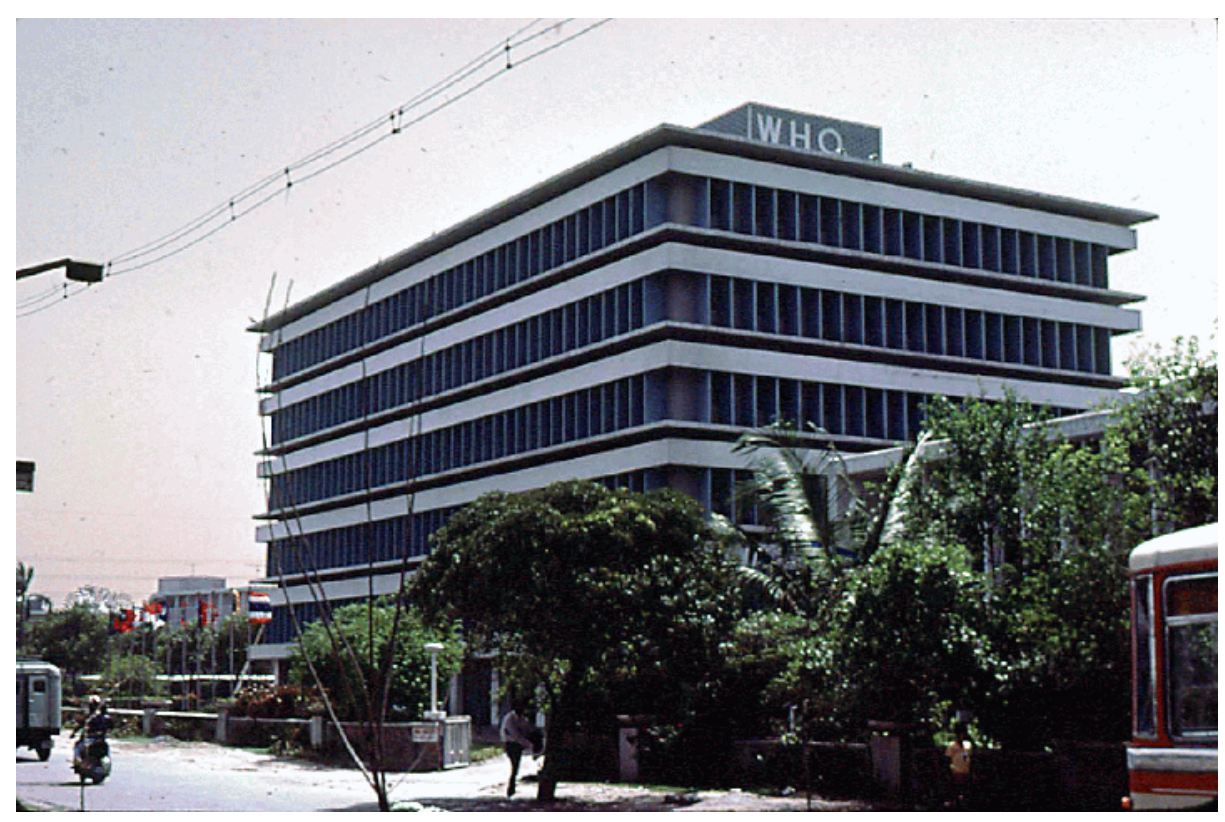


2. Central Institute of Psychiatry, Ranchi, Bihar

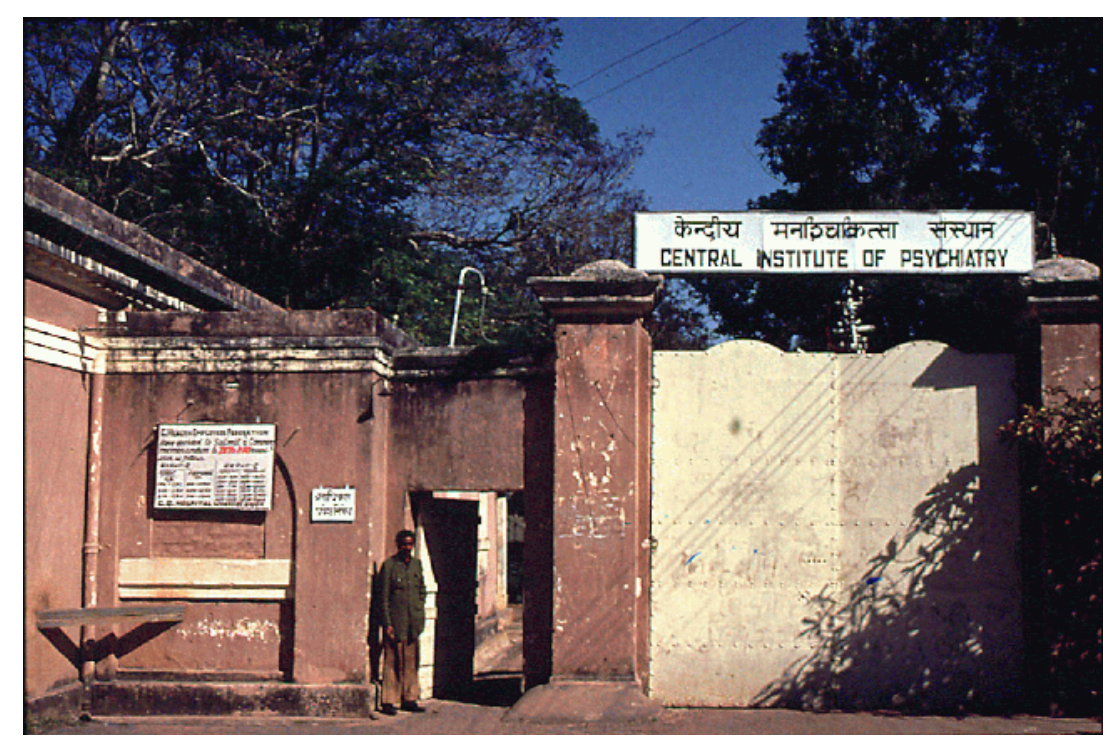


3. Indian Council of Medical Research (ICMR), New Delhi

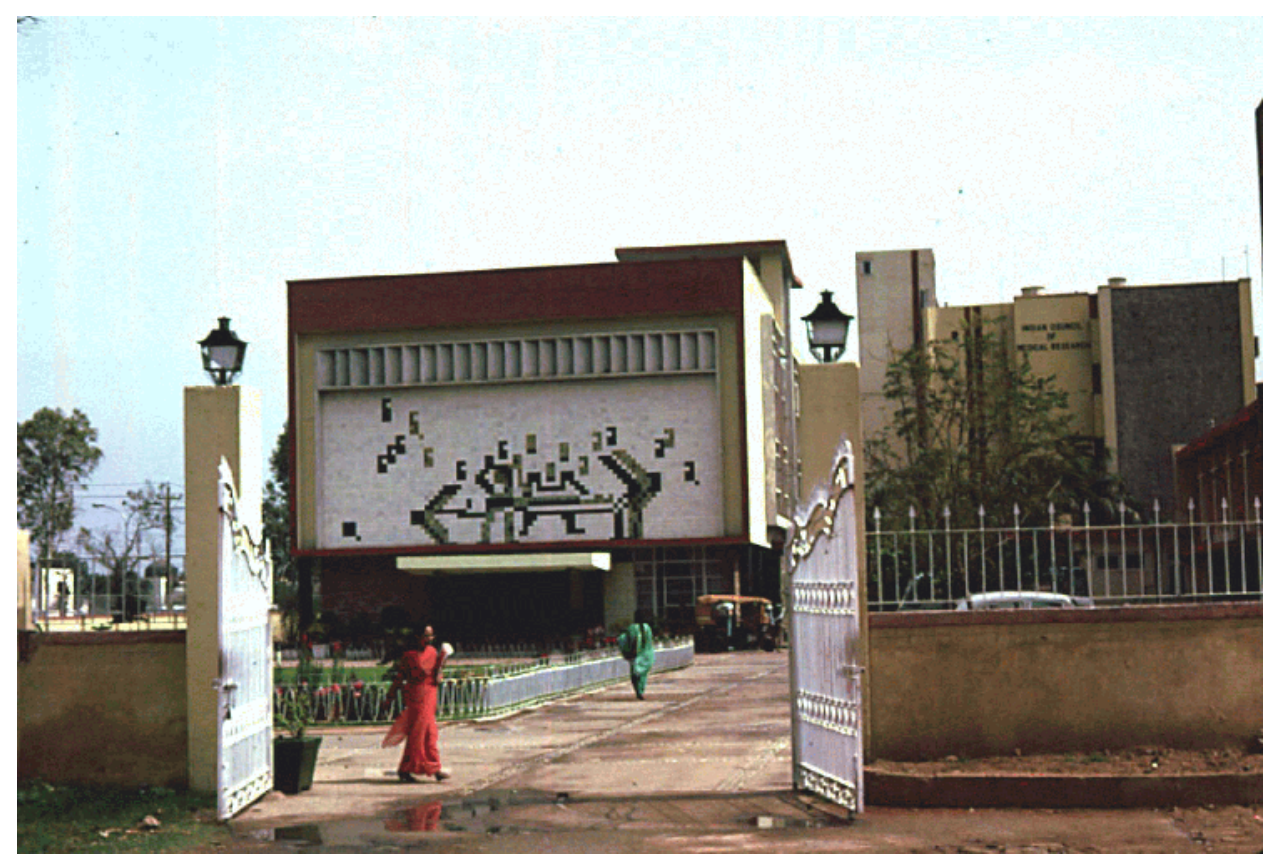


4. Coastal landscape, Sagar Island, West Bengal

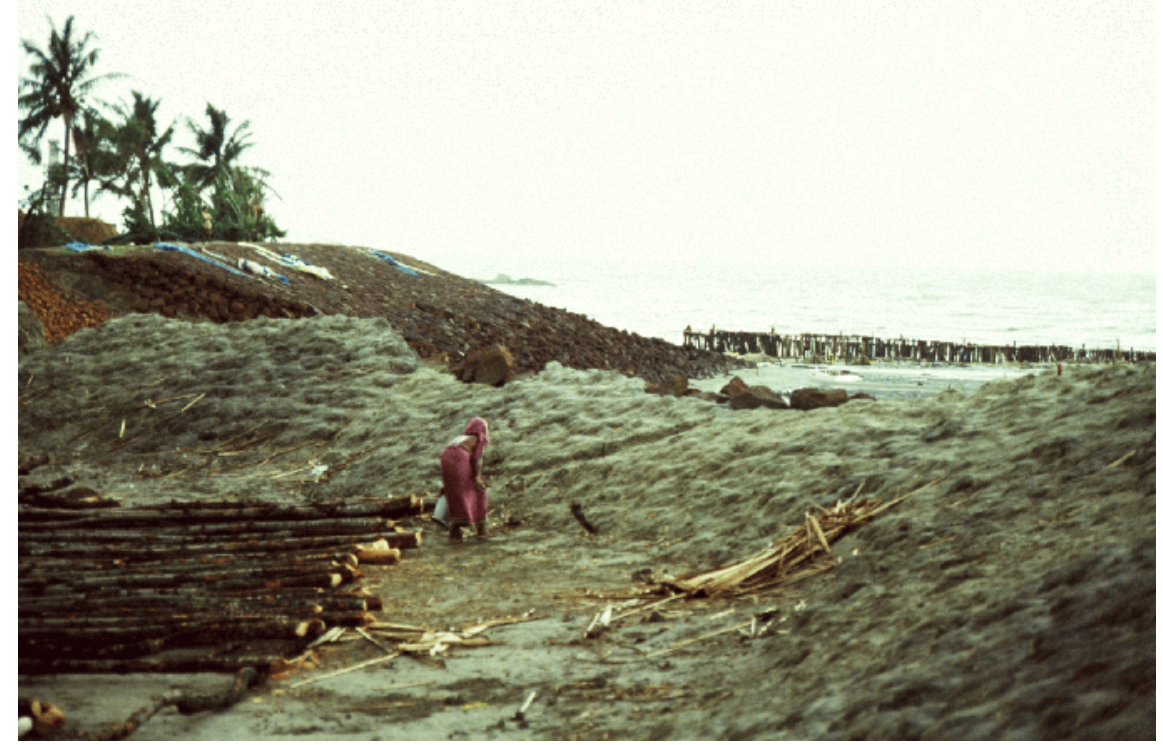


5. Malvani slum community and background of metropolitan Mumbai skyline

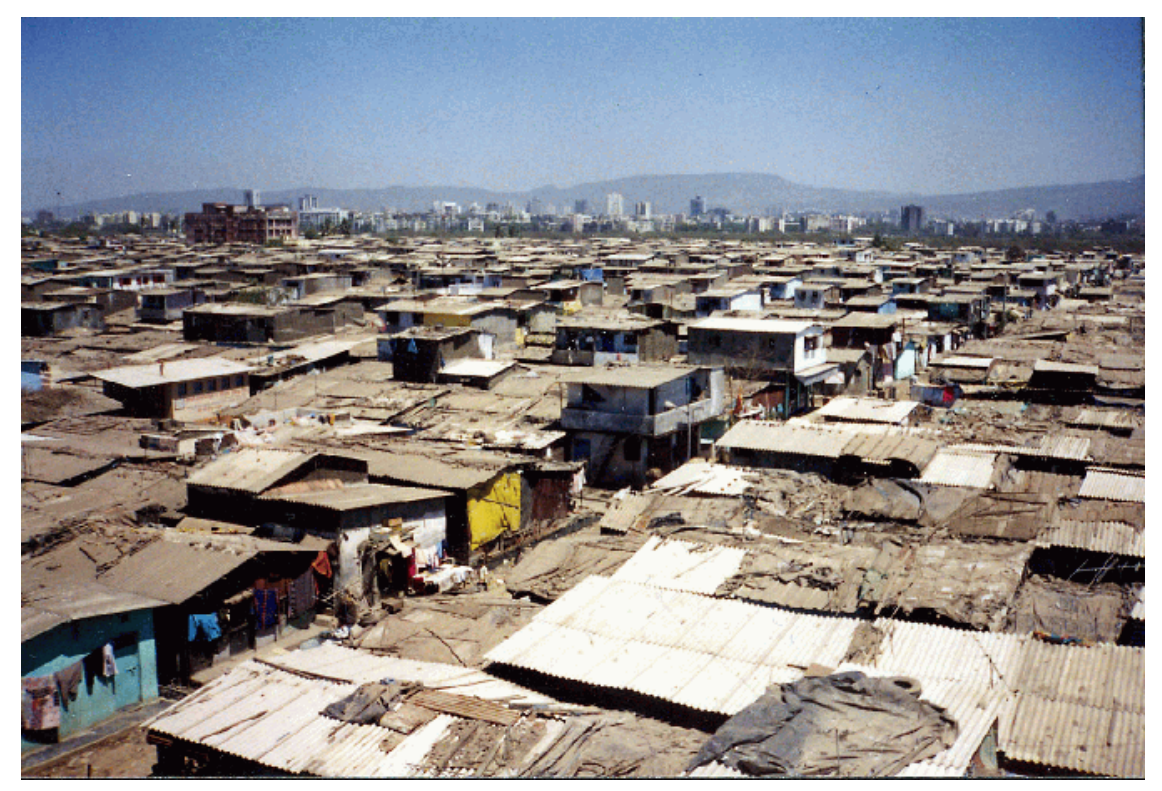

